\title{
Leisure-time physical activity and gastric cancer risk: a pooled study within the Stomach cancer Pooling (StoP) Project
}

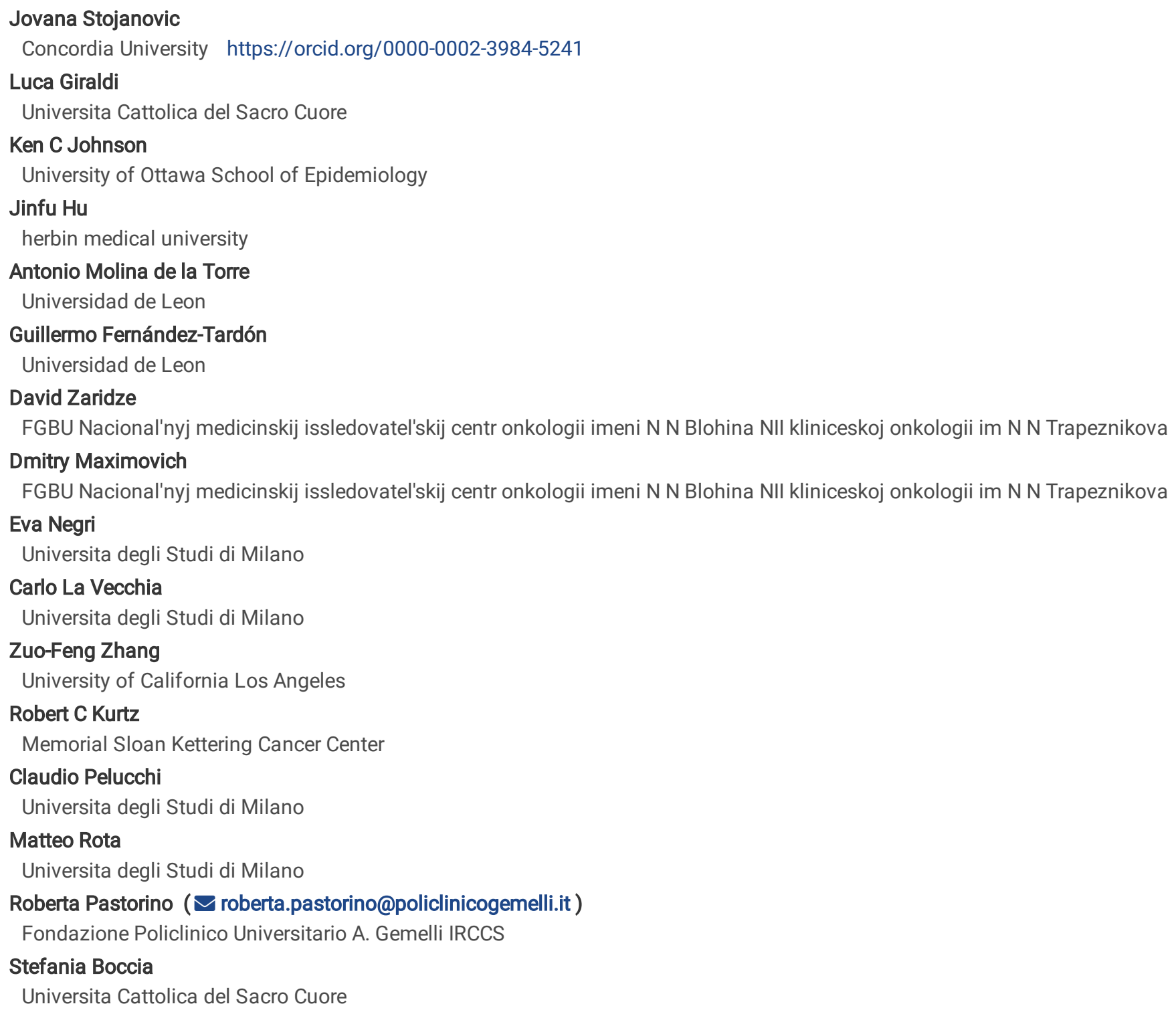

\section{Research}

Keywords: physical activity, gastric cancer, prevention, pooled analysis

Posted Date: March 26th, 2020

DOI: https://doi.org/10.21203/rs.3.rs-19382/v1

License: (c) (7) This work is licensed under a Creative Commons Attribution 4.0 International License. Read Full License 


\section{Abstract}

Background Physical activity (PA) has been recognized as a protective factor against several types of cancer, though robust evidence related to Gastric Cancer (GC) are lacking. This study aimed to establish whether leisure-time PA can prevent GC using data from a large pooled analysis of case-control studies within the Stomach cancer Pooling (StoP) Project.

Methods Five case-control studies from StoP project collected data on PA, for a total of 2,415 cases and 9,722 controls. Subjects were classified into three leisure-time PA categories, either none/low, intermediate or high, based on study-specific tertiles. We used a two-stage approach. Firstly, we applied multivariable logistic regression models to obtain study-specific odds ratios (ORs) and corresponding $95 \%$ confidence intervals (Cls). Afterwards, we used a random-effect models for estimating pooled effect estimates. Heterogeneity across studies was assessed using Q and I 2 statistics. We performed stratified analyses according to demographic, lifestyle and clinical covariates.

Results The pooled ORs for GC risk were 0.90 ( $95 \% \mathrm{Cl}: 0.72,1.13)$ for intermediate, and $0.72(95 \% \mathrm{Cl}: 0.57,0.91)$ for high levels of leisure-time PA. There was no evidence of significant heterogeneity in outcome estimates $($ I $2=49.7 \% ; p=0.094$ for intermediate; $\mid 2=42.9 \%, p=0.135$ for high levels of exposure). GC risk estimates did not differ across strata of selected covariates.

Conclusions Our study is the largest pooled analysis that provides insights about protective effects of high levels of recreational PA on GC risk. Although our results should be confirmed from large cohort studies, the implications have relevant public health significance.

\section{Background}

Gastric cancer (GC) is one of the most common cancers worldwide, particularly in less developed countries, with a wide difference of the incidence rate between males and females $(1,2)$. In most countries, the relative 5 -year survival rate is low, around $30 \%$. In the last few decades, a decline of the incidence rates was observed, mainly because of the recognition of risk factors such as dietary and environmental factors, and H. Pylori infection $(3,4)$. Despite this decline, the trend in incidence of cardia GC remained stable or increased in the Western countries $(5,6)$.

Physical activity (PA) is a complex, multidimensional behavior that represents one of the most important modifiable determinants of all-cause mortality and non-communicable diseases (7). In particular, recreational PA largely incorporates various activities undertaken during leisure time (i.e. walking and hiking, jogging, cycling, swimming etc.) and represents a potentially modifiable component of energy expenditure $(7,8)$. Insufficient levels of PA cause around 3.2 million deaths each year, while 2010 figures show that lack of PA contributed to 69.3 million disability-adjusted life years globally ( $2.8 \%$ of the total) (9). Among plausible biological pathways responsible for the beneficial effects of PA, the literature highlights the following: insulin resistance, growth factors, adipocytokines, steroid hormones, and immune function (10-12).

PA has been intensively studied in relation to several types of cancer, and recent estimates indicate that between 9 and $19 \%$ of the incidence of cancer in Europe could be attributed to physical inactivity $(13,14)$. There is substantial epidemiologic evidence linking inadequate levels of PA with an increased incidence and mortality from colorectal, breast and endometrial cancers $(12,15,16)$. Despite these known benefits, recent WHO estimates conducted on a global level in 2010 indicate that $23 \%$ of adults remain insufficiently active (men $20 \%$ and women $27 \%$ ) (17).

To date, the World Cancer Research Fund has published a series of systematic reviews, showing a lack of firm evidence for the association between PA and GC risk (18). Several meta-analyses evaluated the effect of different domains of PA on GC risk across diverse settings, with risk reductions ranging from 13 to $21 \%$ among the most physically active people (19-22). However, the majority of the included studies did not provide adequate data for conducting subgroup analyses nor did they take in consideration important potential confounders, which may have influenced the results (socio-economic status, dietary habits etc.). The objective of this study was to explore the association between leisuretime PA and GC risk through a pooled analysis of case-control studies within the International "Stomach cancer Pooling Project" (StoP) (23), and to further assess this relationship in strata of selected covariates.

\section{Methods}

\section{Studies and participants}

All the studies participating in the StoP consortium (23) were conducted in accordance with applicable laws, regulations and guidelines for protection of human subjects, and the StoP Project received ethical approval from the University of Milan Review Board (reference no. 19/15 of 01/04/2015). Overall, ten out of over 30 studies included in the latest release (number 2.1) of the StoP dataset collected data on leisure-time PA (24-33). However, five studies were not considered for the present investigation, mainly because available PA variables were characterized by a large amount of missing data or were qualitative in their nature (29-33). Studies with large percentage of missing values on PA were not included (34). Five studies were ultimately included in the pooled analysis: Italy (28), Canada (27), Russia (26), USA (25), and Spain (24). 
The questionnaires administered to study subjects usually include demographic and lifestyle data on PA, cigarette smoking, alcohol use, dietary habits, and family history of cancer. Additional data from the study cases were obtained from cancer registries or hospital medical records. All data were collected and standardized according to a pre-specified format at the data-pooling center.

The main characteristics of PA variables are outlined in Table 1. Studies reported (25-28) the duration (number of hours) of leisure-time PA over a certain interval of time (a week period). In particular, Italian and US centers $(25,28)$ had pre-specified criteria with cut-off points in their questionnaires, while Canada, Russia and Spain $(24,26,27)$ reported continuous values. Only the Canadian center incorporated data on the PA intensity (moderate or vigorous) (27). The period for study-specific PA variables ranged from one year to 5 years.

Since the variables related to leisure-time PA as well as period of referral showed certain levels of variation across the centers, we designed PA exposure category based on study-specific tertiles that were created using control populations. Study subjects were assigned to one of three PA categories, either none/low, intermediate or high (most commonly expressed as number of hours engaging in recreational PA across a week period). None and low levels of exposure were combined together due to the nature of individual study questionnaires and were considered as a reference category.

\section{Statistical analysis}

Descriptive analyses were conducted to describe the study population in terms of demographic characteristics, selected lifestyle habits, GC characteristics (subsite and histotype) and H. pylori infection. The relationship between PA and GC was evaluated using a two-stage approach (35). Firstly, multivariable logistic regression models were applied to obtain study-specific odds ratios (ORs) and the corresponding $95 \%$ Confidence Intervals (Cls). These models were adjusted for sex, age, H. Pylori, smoking, alcohol consumption, BMI, social class, occupational PA, cancer history, and dietary habits (Additional file 1). In the second phase, a random-effect model was applied in order to estimate summary (pooled) effect measures. Heterogeneity across studies was assessed with the $\mathrm{Q}$ and $P^{2}$ statistics measures (36).

In order to investigate the effects of leisure-time PA across strata of selected covariates, we performed stratified analyses according to: sex, age $(\leq 55,56-65,>65)$, BMI (normal weight, overweight, obese), social class (study-specific low, intermediate, high), smoking status (never, former, current smoker), alcohol drinking status (never, ever), vegetables and fruit intake (study-specific low, intermediate, high), occupational PA (study-specific low, intermediate, high), cancer history among first degree relatives (yes, no), GC subsite (cardia, non-cardia), GC histotype (intestinal, diffuse, undifferentiated) and H. Pylori status (positive, negative). Heterogeneity tests were performed across all the strata estimates. Lastly, we performed a test for linear trend across the three levels of PA variable (37).

All statistical tests were two-sides and a p-value $<0.05$ was considered as statistically significant. Statistical analyses were carried out using STATA software, version 12 .

\section{Results}

The main characteristics of the 2,415 cases and 9,722 controls included in the present analysis are reported in Table 2. Two-thirds (65\%) of GC cases were men. Cases were fairly older than controls and more commonly belonged to lower social classes ( $41.7 \%$ in cases vs $38.3 \%$ in controls). Majority of study subjects showed none or low levels of PA ( $47.8 \%$ among cases and $43 \%$ among controls). The proportion of current smokers was similar across cases $(18.8 \%)$ and controls $(20 \%)$, while cases were more likely to consume high levels of alcoholic beverages than controls ( $15.2 \%$ vs $6.8 \%$, respectively). Furthermore, the percentage of obese subjects was slightly higher among cases in respect to controls ( $16.2 \%$ vs $15.8 \%$, respectively). Considering information on cases of GC, the vast majority were non-cardia site (46.2\%). Regarding information on $H$. Pylori status, the data were available for two study centers $(24,26)$.

The pooled ORs of different levels of leisure-time PA are reported in Figure 1. The overall pooled OR was 0.90 ( $95 \% \mathrm{Cl}: 0.72,1.13)$ for subjects with an intermediate level of PA versus none/low levels, and $0.72(95 \% \mathrm{Cl}: 0.57,0.91)$ for high levels of PA. There was no evidence of a significant trend in risk estimates and no significant heterogeneity for either intermediate $(R=49.7 \% ; \mathrm{p}=0.094)$ or high levels of exposure $\left(R^{2}=\right.$ $42.9 \%, \mathrm{p}=0.135)($ Fig 1$)$.

The results show the absence of a meaningful effect modification from the variables considered, although we reported a noticeable stronger effect among non-cardia tumor site ( $\mathrm{OR}=0.59 ; 95 \% \mathrm{Cl}: 0.42,0.84$ for high levels of $\mathrm{PA}$, and $\mathrm{OR}=0.77 ; 95 \% \mathrm{Cl}: 0.60,0.98$ for intermediate levels of PA).

When evaluating studies with available information on H.Pylori status, our results indicated a lack of statistically significant association both for high and intermediate levels of PA (Table 3).

\section{Discussion}


Our study evaluated the association between leisure-time PA and GC risk by pooling data from five case-control studies of the StoP consortium, totaling to 2,415 cases and 9,722 controls. The overall pooled estimates report a $28 \%$ reduced risk of GC among individuals practicing high levels of leisure-time PA $(\mathrm{OR}=0.72 ; 95 \% \mathrm{Cl}: 0.57,0.91)$. We also reported a protective effect of intermediate and high levels of $\mathrm{PA}$ among non-cardia GC cases with a trend in outcome estimates (OR $=0.77 ; 95 \% \mathrm{Cl}$ : 0.60, 0.98 for intermediate PA and $\mathrm{OR}=0.59 ; 95 \% \mathrm{Cl}$ : $0.42,0.84$ for high PA).

Our study findings are in line with the most recent meta-analyses on the effects of PA on GC, where authors reported a protective effect of PA on GC development (19-22). In the most recent meta-analysis(22) including 10 cohort and 12 case-control studies, results showed a 19\% reduced risk for GC among the persons in the highest category of any PA compared to the lowest (22). However, when restricting the analysis to data on recreational PA and including nine case control studies (3045 cases and 21,128 controls) and seven cohort studies (4814 cases), the meta-analysis reported non-significant effect estimates (pooled OR for case-control studies $=0.86,95 \% \mathrm{Cl}(0.69-1.07)$; pooled risk ratio $(\mathrm{RR})$ for cohort studies $=0.92,95 \% \mathrm{Cl}(0.74-1.15)$ ). Significant protective effects, however, were reported from two cohort studies including non-cardia GC cases (pooled RR = 0.62; 95\% Cl: 0.52-0.75) (22). Additional pooled analyses of 12 US and EU cohorts with around 1.44 million participants showed a protective, but non-significant, association among 1428 non-cardia GC cases (hazard ratio (HR) = 0.93, 95\% Cl: 0.73 , 1.19) when comparing high versus low levels of leisure-time PA (14). In accordance with these findings, our analysis suggests a reduced GC risk among individuals with non-cardia GC engaging both in intermediate and high levels of PA levels compared to none/low levels. The biological mechanisms by which PA affects cancer development cover mostly indirect beneficial effects of PA on adiposity: lowering the levels of circulating adipokines, improving insulin resistance and blood insulin levels, but also lowering the production of sex hormones and inflammatory cytokines $(7,12,38)$. There are several factors that can influence PA effects and they may or may not be PA related (i.e. type, duration, intensity of activity, but also age, sex, adiposity etc.) $(38,39)$. The literature regarding modifying effects of sex and BMI is quite conflicting. Some studies showed a stronger inverse association among women due to negative effects of estrogen levels on the growth of gastric tumors (40). On the other hand, recent review reported only $1 \%$ weaker association in men compared to women and $10 \%$ weaker association as BMI increases with near significant findings (21). Another study showed the effects of PA on gastroesophageal cancer risk change only slightly when meta-analyzing studies that adjusted for adiposity (40). Our study showed a lack of significant heterogeneity in the stratified analyses by sex and weight. It is worth noting that all of the models in the present analysis were sex and BMI adjusted, which may suggest that observed effects of PA on GC are not entirely influenced through its effects on weight $(20,41)$.

Both alcohol and smoking are known to increase the risk of GC. Heavy drinkers are associated with approximately $50 \%$ increased risk of GC, while smokers of more than 20 cigarettes per day have around 30\% greater risk for developing the disease $(42,43)$. Although significant risk reductions were observed among ever drinkers, former and current smokers in our analyses, we did not observe significant effect modification due to alcohol and smoking when comparing high to none/low levels of PA. One recent analyses exploring the associations between exercise, smoking and mortality from various causes may complement our findings. O'Donovan et al. (44) followed 106,341 individuals and suggested that physical exercise may reduce the risk of overall cancer mortality by around $30 \%$ both in current and ex-smokers. In contrast, a metaregression of studies on GC suggested that tobacco smoking may reduce the positive effect of PA on GC, particularly among individuals practicing sufficient levels of PA (21). The present study and conflicting previous literature imply that the complex interlink between behavioral risk factors and PA and their mutual effects on cancer development is yet to be disentangled (7).

Our results implicate no substantial differences in the risk estimates according to occupational PA strata. These findings are somewhat expected, since previous research reported no evidence of the effect of occupational PA on GC risk $(45,46)$. The European Prospective Investigation into Cancer and Nutrition (EPIC) cohort observed no increase in risk of GC among sedentary occupations in comparison to manual or standing occupations (47). Individuals of lower socio-economic positions and employed in manual occupations tend to engage in less leisure-time PA (48). However, a causal relationship between job position and health outcomes is far more complex and prone to influence of various factors including socioeconomic indicators such as education and wealth (49). EPIC data reported a reduction in GC risk among populations of higher educational level. In a nested case-control study from this cohort, these effects were largely attenuated after adjusting for a known risk factor - H. Pylori (50). In that sense, adjustments for social class position in our statistical models are of particular importance in the present research.

The limitations of our study are mainly due to the fact that data regarding recreational PA were collected by study-specific questionnaires with different definitions and classifications. In order to make the available information comparable, we defined three levels of PA intensity based on study specific tertiles (44). This might have led to information misclassification of the exposure. In addition, data on PA was collected at different time points prior to GC diagnosis, i.e. from one year up to 5 years and this might have contributed to non-differential misclassification of PA exposure. Another limitation is the lack of information on $\mathrm{H}$. Pylori infection that was available only in two study centers (24,26). Besides adjusting for $\mathrm{H}$. Pylori status in study specific regression models, we have also provided a stratified analysis including only individuals with available information. 
Our study has some important strengths. First of all, it represents the solely pooled analyses of case-control studies that was able to adjust the results for the most important confounding factors of GC. These adjustments are extremely important when evaluating the complex relationship between PA and cancer, especially when taking into account that cancer development is a multifactorial and site-specific process and that PA may act through multiple biological pathways. Secondly, our analyses included a substantial number of GC cases enabling us to evaluate the outcomes across the strata of different behavioral risk factors and clinical features.

\section{Conclusions}

This study represents the first pooled analysis of observational studies exploring the association between leisure-time PA and risk of GC. We provide positive insights about the preventive role of high amounts of leisure-time PA on GC development. Future studies should develop and implement standardized data collection procedures that could facilitate further evaluations of the role of PA in cancer prevention.

\section{Abbreviations}

GC - Gastric cancer

PA - Physical activity

StoP - Stomach cancer Pooling Project

OR - Odds ratios

Cls - 95\% Confidence Intervals

HR - hazard ratio

RR - Risk ratio

EPIC - The European Prospective Investigation into Cancer and Nutrition

\section{Declarations}

Ethics approval and consent to participate

StoP Project received ethical approval from the University of Milan Review Board (reference no. 19/15 of 01/04/2015).

\section{Consent for publication}

Not applicable.

\section{Availability of data and material}

This study brought together existing data obtained upon request and subject to licence restrictions from a number of different sources. Full details of how these datasets were obtained are available in the documentation available at 10.1097/CEJ.0000000000000017

\section{Competing interests}

The authors declare that they have no competing interests.

\section{Funding}

This work was supported by the Italian Ministry of Health (project code GR-2011-02347943 to SB). The funding body did not have a role in the design of the study and collection, analysis, and interpretation of data and manuscript writing.

\section{Authors' contributions}

SJ, LG, PR and SB were involved in the conception of the work. SJ and GL performed the analysis. All the authors were involved in data acquisition. PR, BS, PC, RM, NE, LVC, MTAJ, and FTG were involved in the interpretation of the data. SJ, LG, PR and SB were responsible for drafting the work. All the authors were involved in substantial revision and making improvements to the work as well as approval of the submitted version. 


\section{Acknowledgements}

Not applicable.

\section{References}

1. Ferlay J, Soerjomataram I, Dikshit R, Eser S, Mathers C, Rebelo M, et al. Cancer incidence and mortality worldwide: sources, methods and major patterns in GLOBOCAN 2012. Int J cancer [Internet]. 2015 Mar 1 [cited 2018 Aug 9];136(5):E359-86. Available from: http://doi.wiley.com/10.1002/ijc.29210

2. Boffetta P, Boccia S, La Vecchia C. Distribution, Causes and Prevention of Individual Neoplasms. In: A Quick Guide to Cancer Epidemiology [Internet]. Cham: Springer International Publishing; 2014 [cited 2018 Aug 9]. p. 15-75. Available from:

http://link.springer.com/10.1007/978-3-319-05068-3_4

3. den Hoed CM, Kuipers EJ. Gastric Cancer: How Can We Reduce the Incidence of this Disease? Curr Gastroenterol Rep [Internet]. 2016 Jul 16 [cited 2018 Aug 9];18(7):34. Available from: http://link.springer.com/10.1007/s11894-016-0506-0

4. Sitarz R, Skierucha M, Mielko J, Offerhaus J, Maciejewski R, Polkowski W. Gastric cancer: epidemiology, prevention, classification, and treatment. Cancer Manag Res [Internet]. 2018 Feb [cited 2018 Aug 9];Volume 10:239-48. Available from: http://www.ncbi.nlm.nih.gov/pubmed/29445300

5. Colquhoun A, Arnold M, Ferlay J, Goodman KJ, Forman D, Soerjomataram I. Global patterns of cardia and non-cardia gastric cancer incidence in 2012. Gut [Internet]. 2015 Dec [cited 2018 Aug 9];64(12):1881-8. Available from:

http://gut.bmj.com/lookup/doi/10.1136/gutjnl-2014-308915

6. Camargo MC, Anderson WF, King JB, Correa P, Thomas CC, Rosenberg PS, et al. Divergent trends for gastric cancer incidence by anatomical subsite in US adults. Gut [Internet]. 2011 Dec 1 [cited 2018 Aug 9];60(12):1644-9. Available from: http://gut.bmj.com/cgi/doi/10.1136/gut.2010.236737

7. Leitzmann M, Powers H, Anderson AS, Scoccianti C, Berrino F, Boutron-Ruault M-C, et al. European Code against Cancer 4th Edition: Physical activity and cancer. Cancer Epidemiol [Internet]. 2015 Dec [cited 2018 Aug 9];39:S46-55. Available from: http://www.ncbi.nlm.nih.gov/pubmed/26187327

8. Hurd AR, Anderson DM. The park and recreation professional's handbook [Internet]. Human Kinetics; 2011 [cited 2018 Aug 9 ]. 300 p. Available from: https://uk.humankinetics.com/products/park-and-recreation-professionals-handbook-with-online-resource-the

9. Lim SS, Vos T, Flaxman AD, Danaei G, Shibuya K, Adair-Rohani H, et al. A comparative risk assessment of burden of disease and injury attributable to 67 risk factors and risk factor clusters in 21 regions, 1990-2010: a systematic analysis for the Global Burden of Disease Study 2010. Lancet (London, England) [Internet]. 2012 Dec 15 [cited 2018 Aug 9];380(9859):2224-60. Available from: http://linkinghub.elsevier.com/retrieve/pii/S0140673612617668

10. World Cancer Research Fund /American Institute For Cancer Research. Continous Update Project Expert Report 2018. Physical activity and the risk of cancer [Internet]. 2018 [cited 2018 Aug 9]. Available from: dietandcancerreport.org

11. Brown JC, Winters-Stone K, Lee A, Schmitz KH. Cancer, Physical Activity, and Exercise. [cited 2018 Aug 9]; Available from: https://wwwncbi-nlm-nih-gov.pisana.clas.cineca.it/pmc/articles/PMC4122430/pdf/nihms602193.pdf

12. Kerr J, Anderson C, Lippman SM. Physical activity, sedentary behaviour, diet, and cancer: an update and emerging new evidence. Lancet Oncol [Internet]. 2017 Aug [cited 2018 Aug 9];18(8):e457-71. Available from: http://www.ncbi.nlm.nih.gov/pubmed/28759385

13. Friedenreich CM, Neilson HK, Lynch BM. State of the epidemiological evidence on physical activity and cancer prevention. Eur J Cancer [Internet]. 2010 Sep [cited 2018 Aug 9];46(14):2593-604. Available from: http://linkinghub.elsevier.com/retrieve/pii/S0959804910007069

14. Moore SC, Lee I-M, Weiderpass E, Campbell PT, Sampson JN, Kitahara CM, et al. Association of Leisure-Time Physical Activity With Risk of 26 Types of Cancer in 1.44 Million Adults. JAMA Intern Med [Internet]. 2016 Jun 1 [cited 2018 Aug 9];176(6):816-25. Available from: http://archinte.jamanetwork.com/article.aspx?doi=10.1001/jamainternmed.2016.1548

15. World Health Organization. Global health risks: Mortality and burden of disease attributable to selected major risks [Internet]. Geneva, Switzerland; 2009 [cited 2018 Aug 9]. Available from:

http://www.who.int/healthinfo/global_burden_disease/GlobalHealthRisks_report_full.pdf

16. Rezende LFM de, Sá TH de, Markozannes G, Rey-López JP, Lee I-M, Tsilidis KK, et al. Physical activity and cancer: an umbrella review of the literature including 22 major anatomical sites and 770000 cancer cases. Br J Sports Med [Internet]. 2017 Nov 16 [cited 2018 Aug 9];52(13):bjsports-2017-098391. Available from: http://www.ncbi.nlm.nih.gov/pubmed/29146752

17. World Health Organization. Global recommendations on physical activity for health. [Internet]. 2010 [cited 2018 Aug 9]. Available from: http://apps.who.int/iris/bitstream/handle/10665/44399/9789241599979_eng.pdf;jsessionid=52132C7B07640D81D4DC77669B2C8071? sequence $=1$ 
18. World Cancer Research Fund / American Institute for Cancer Research. Diet, Nutrition, Physical Activity and Cancer: a Global Perspective. Continous Update Project Expert Report 2018. [Internet]. Washington; [cited 2018 Aug 9]. Available from: https://www.wcrf.org/dietandcancer

19. Chen Y, Yu C, Li Y. Physical activity and risks of esophageal and gastric cancers: a meta-analysis. Zhang Z, editor. PLoS One [Internet]. 2014 Feb 6 [cited 2018 Aug 9];9(2):e88082. Available from: http://dx.plos.org/10.1371/journal.pone.0088082

20. Singh S, Edakkanambeth Varayil J, Devanna S, Murad MH, lyer PG. Physical activity is associated with reduced risk of gastric cancer: a systematic review and meta-analysis. Cancer Prev Res (Phila) [Internet]. 2014 Jan 1 [cited 2018 Aug 9];7(1):12-22. Available from: http://cancerpreventionresearch.aacrjournals.org/cgi/doi/10.1158/1940-6207.CAPR-13-0282

21. Abioye Al, Odesanya MO, Abioye Al, Ibrahim NA. Physical activity and risk of gastric cancer: a meta-analysis of observational studies. Br $\mathrm{J}$ Sports Med [Internet]. 2015 Feb [cited 2018 Aug 9];49(4):224-9. Available from: http://bjsm.bmj.com/lookup/doi/10.1136/bjsports-2013092778

22. Psaltopoulou T, Ntanasis-Stathopoulos I, Tzanninis I-G, Kantzanou M, Georgiadou D, Sergentanis TN. Physical Activity and Gastric Cancer Risk: A Systematic Review and Meta-Analysis. Clin J Sport Med [Internet]. 2016 Nov [cited 2018 Aug 9];26(6):445-64. Available from: http://content.wkhealth.com/linkback/openurl?sid=WKPTLP:landingpage\&an=00042752-201611000-00002

23. Pelucchi C, Lunet N, Boccia S, Zhang Z-F, Praud D, Boffetta P, et al. The stomach cancer pooling (StoP) project: study design and presentation. Eur J Cancer Prev [Internet]. 2015 Jan [cited 2018 Aug 9];24(1):16-23. Available from: https://insights.ovid.com/crossref? an=00008469-201501000-00003

24. Castaño-Vinyals G, Aragonés N, Pérez-Gómez B, Martín V, Llorca J, Moreno V, et al. Population-based multicase-control study in common tumors in Spain (MCC-Spain): rationale and study design. Gac Sanit [Internet]. 2015 Jul [cited 2018 Aug 9];29(4):308-15. Available from: http://linkinghub.elsevier.com/retrieve/pii/S021391111400288X

25. Zhang ZF, Kurtz RC, Klimstra DS, Yu GP, Sun M, Harlap S, et al. Helicobacter pylori infection on the risk of stomach cancer and chronic atrophic gastritis. Cancer Detect Prev [Internet]. 1999 [cited 2018 Aug 9];23(5):357-67. Available from: http://www.ncbi.nlm.nih.gov/pubmed/10468887

26. Zaridze D, Borisova E, Maximovitch D, Chkhikvadze V. Alcohol consumption, smoking and risk of gastric cancer: case-control study from Moscow, Russia. Cancer Causes Control [Internet]. 2000 Apr [cited 2018 Aug 9];11(4):363-71. Available from: http://www.ncbi.nlm.nih.gov/pubmed/10843447

27. Mao Y, Hu J, Semenciw R, White K, Canadian Cancer Registries Epidemiology Research Group. Active and passive smoking and the risk of stomach cancer, by subsite, in Canada. Eur J Cancer Prev [Internet]. 2002 Feb [cited 2018 Aug 9];11(1):27-38. Available from: http://www.ncbi.nlm.nih.gov/pubmed/11917206

28. Lucenteforte E, Scita V, Bosetti C, Bertuccio P, Negri E, La Vecchia C. Food groups and alcoholic beverages and the risk of stomach cancer: a case-control study in Italy. Nutr Cancer [Internet]. 2008 [cited 2016 Jun 13];60(5):577-84. Available from: http://www.ncbi.nlm.nih.gov/pubmed/18791920

29. De Feo E, Simone B, Persiani R, Cananzi F, Biondi A, Arzani D, et al. A case-control study on the effect of Apolipoprotein E genotypes on gastric cancer risk and progression. BMC Cancer [Internet]. 2012 Oct 25 [cited 2018 Sep 11];12:494. Available from: http://www.ncbi.nlm.nih.gov/pubmed/23098561

30. Mu L-N, Lu Q-Y, Yu S-Z, Jiang Q-W, Cao W, You N-C, et al. Green tea drinking and multigenetic index on the risk of stomach cancer in a Chinese population. Int J cancer [Internet]. 2005 Oct 10 [cited 2018 Sep 26];116(6):972-83. Available from: http://doi.wiley.com/10.1002/ijc.21137

31. Lagiou P, Samoli E, Lagiou A, Peterson J, Tzonou A, Dwyer J, et al. Flavonoids, vitamin C and adenocarcinoma of the stomach. Cancer Causes Control. 2004 Feb;15(1):67-72.

32. H Harris, N Håkansson, C Olofsson, O Stackelberg, B Julin, A Åkesson AW. The Swedish mammography cohort and the cohort of Swedish men: study design and characteristics of two population-based longitudinal cohorts.OA Epidemiology. OA Epidemiol [Internet]. 2013 [cited 2018 Sep 26];1(2):16. Available from: http://www.oapublishinglondon.com/article/943

33. Matsuo K, Oze I, Hosono S, Ito H, Watanabe M, Ishioka K, et al. The aldehyde dehydrogenase 2 (ALDH2) Glu504Lys polymorphism interacts with alcohol drinking in the risk of stomach cancer. Carcinogenesis [Internet]. 2013 Jul 1 [cited 2018 Sep 26];34(7):1510-5. Available from: http://www.ncbi.nlm.nih.gov/pubmed/23455379

34. Bennett DA. How can I deal with missing data in my study? Aust N Z J Public Health [Internet]. 2001 Oct [cited 2019 Mar 19];25(5):464-9. Available from: http://www.ncbi.nlm.nih.gov/pubmed/11688629

35. Smith-Warner SA, Spiegelman D, Ritz J, Albanes D, Beeson WL, Bernstein L, et al. Methods for pooling results of epidemiologic studies: the Pooling Project of Prospective Studies of Diet and Cancer. Am J Epidemiol [Internet]. 2006 Jun 1 [cited 2018 Aug 9];163(11):1053-64. Available from: http://academic.oup.com/aje/article/163/11/1053/168399/Methods-for-Pooling-Results-of-Epidemiologic 
36. Higgins JPT, Thompson SG, Deeks JJ, Altman DG. Measuring inconsistency in meta-analyses. BMJ [Internet]. 2003 Sep 6 [cited 2018 Aug 9];327(7414):557-60. Available from: http://www.bmj.com/cgi/doi/10.1136/bmj.327.7414.557

37. Patino CM, Ferreira JC. Test for trend: evaluating dose-response effects in association studies. J Bras Pneumol [Internet]. 2016 [cited 2019 Feb 19];42(4):240. Available from: http://www.ncbi.nlm.nih.gov/pubmed/27832229

38. McTiernan A. Mechanisms linking physical activity with cancer. Nat Rev Cancer [Internet]. 2008 Mar 1 [cited 2018 Aug 9];8(3):205-11. Available from: http://www.ncbi.nlm.nih.gov/pubmed/18235448

39. Ayán C, Cancela J, Molina A, Fernández T, Martín V. Methodological issues when analysing the role of physical activity in gastric cancer prevention: a critical review. Eur Rev Aging Phys Act [Internet]. 2013 Apr 19 [cited 2018 Aug 9];10(1):7-13. Available from: http://link.springer.com/10.1007/s11556-012-0113-5

40. Behrens G, Jochem C, Keimling M, Ricci C, Schmid D, Leitzmann MF. The association between physical activity and gastroesophageal cancer: systematic review and meta-analysis. Eur J Epidemiol [Internet]. 2014 Mar 6 [cited 2018 Aug 9];29(3):151-70. Available from: http://www.ncbi.nlm.nih.gov/pubmed/24705782

41. Byers T. Physical activity and gastric cancer: so what? An epidemiologist's confession. Cancer Prev Res (Phila) [Internet]. 2014 Jan 1 [cited 2018 Aug 9];7(1):9-11. Available from: http://cancerpreventionresearch.aacrjournals.org/cgi/doi/10.1158/1940-6207.CAPR-13-0400

42. Praud D, Rota M, Pelucchi C, Bertuccio P, Rosso T, Galeone C, et al. Cigarette smoking and gastric cancer in the Stomach Cancer Pooling (StoP) Project. Eur J Cancer Prev [Internet]. 2018 Mar [cited 2019 Feb 19];27(2):124-33. Available from: http://www.ncbi.nlm.nih.gov/pubmed/27560662

43. Rota M, Pelucchi C, Bertuccio P, Matsuo K, Zhang Z-F, Ito H, et al. Alcohol consumption and gastric cancer risk-A pooled analysis within the StoP project consortium. Int J Cancer [Internet]. 2017 Nov 15 [cited 2019 Feb 19];141(10):1950-62. Available from: http://www.ncbi.nlm.nih.gov/pubmed/28718913

44. O'Donovan G, Hamer M, Stamatakis E. Relationships between exercise, smoking habit and mortality in more than 100,000 adults. Int $\mathrm{J}$ Cancer [Internet]. 2017 Apr 15 [cited 2019 Feb 19];140(8):1819-27. Available from: http://www.ncbi.nlm.nih.gov/pubmed/28108995

45. Vigen C, Bernstein L, Wu AH. Occupational physical activity and risk of adenocarcinomas of the esophagus and stomach. Int $\mathrm{J}$ cancer [Internet]. 2006 Feb 15 [cited 2018 Aug 9];118(4):1004-9. Available from: http://doi.wiley.com/10.1002/ijc.21419

46. Huerta JM, Chirlaque MD, Molina AJ, Amiano P, Martín V, Fernández-Villa T, et al. Physical activity domains and risk of gastric adenocarcinoma in the MCC-Spain case-control study. Ali R, editor. PLoS One [Internet]. 2017 Jul 6 [cited 2018 Aug 9];12(7):e0179731. Available from: http://www.ncbi.nlm.nih.gov/pubmed/28683070

47. Huerta JM, Navarro C, Chirlaque M-D, Tormo M-J, Steindorf K, Buckland G, et al. Prospective study of physical activity and risk of primary adenocarcinomas of the oesophagus and stomach in the EPIC (European Prospective Investigation into Cancer and nutrition) cohort. Cancer Causes Control [Internet]. 2010 May 6 [cited 2018 Aug 9];21(5):657-69. Available from: http://link.springer.com/10.1007/s10552009-9493-x

48. Burton NW, Turrell G. Occupation, hours worked, and leisure-time physical activity. Prev Med (Baltim) [Internet]. 2000 Dec [cited 2018 Aug 9];31(6):673-81. Available from: http://linkinghub.elsevier.com/retrieve/pii/S0091743500907631

49. Clougherty JE, Souza K, Cullen MR. Work and its role in shaping the social gradient in health. Ann N Y Acad Sci [Internet]. 2010 Feb [cited 2018 Aug 9];1186(1):102-24. Available from: http://doi.wiley.com/10.1111/j.1749-6632.2009.05338.x

50. Nagel G, Linseisen J, Boshuizen HC, Pera G, Del Giudice G, Westert GP, et al. Socioeconomic position and the risk of gastric and oesophageal cancer in the European Prospective Investigation into Cancer and Nutrition (EPIC-EURGAST). Int J Epidemiol [Internet]. 2007 Feb 1 [cited 2018 Aug 9];36(1):66-76. Available from: https://academic.oup.com/ije/article-lookup/doi/10.1093/ije/dyl275

\section{Tables}

Table 1. Study specific definitions for PA and derived tertiles. Stomach cancer pooling (StoP) Project consortium. 


\begin{tabular}{|c|c|c|}
\hline $\begin{array}{l}\text { Study } \\
\text { center }\end{array}$ & Study-specific definition & Study-specific tertiles \\
\hline Italy & Sport, leisure, activities, bycicle rides at various ages $(12,15-19,30-39,50-59)$. & $\begin{array}{l}\text { None/Low: }<2 \text { hours per week } \\
\text { Intermediate: } 2-7 \text { hours per week } \\
\text { High: }>7 \text { hours per week }\end{array}$ \\
\hline Canada & $\begin{array}{l}\text { Number of hours per week spent doing both moderate and strenuous activities (walking, jogging, gardening, home exercises, golf, racquet sports, } \\
\text { bowling, swimming, skiing or skating, bicycling, social dancing and other) averaged over seasons and related to } 2 \text { years before the interview. }\end{array}$ & $\begin{array}{l}\text { None/Low: }=0 \text { hours per week } \\
\text { Intermediate: }>0 \& \leq 2.93 \text { hours per } \\
\text { week } \\
\text { High: }>2.93 \text { hours per week }\end{array}$ \\
\hline Russia & $\begin{array}{l}\text { Walking and sport activities (hours per week) during summer/winter seasons and referring to } 1 \text { year preceding the disease (cases and hospital } \\
\text { controls) and } 1 \text { year prior to the interview for visitor controls. }\end{array}$ & $\begin{array}{l}\text { None/Low: } \leq 0.33 \text { hours per week } \\
\text { Intermediate: }>0.33 \& \leq 0.7 \text { hours } \\
\text { per week } \\
\text { High: }>0.7 \text { hours per week }\end{array}$ \\
\hline USA & $\begin{array}{l}\text { Frequency of certain activities (active sports, physical exercise, jogging-running, swimming/long walks, gardening/fishing/hunting, other } \\
\text { activities) }\end{array}$ & $\begin{array}{l}\text { None/Low: few times a year or } \\
\text { rarely/never engaging in any kind of } \\
\text { rPA } \\
\text { Intermediate: } 1 \text { hour per week or } \\
\text { few times per month of any kind of } \\
\text { rPA } \\
\text { High: }>1 \text { hour per week of any kind } \\
\text { of rPA }\end{array}$ \\
\hline Spain & $\begin{array}{l}\text { PA defined as activities that took place outside working hours, including walking, doing some sport, going to the gym, etc. in the last } 5 \text { years and } \\
\text { for a period of at least } 6 \text { months (excluding } 1 \text { year prior to diagnosis) }\end{array}$ & $\begin{array}{l}\text { None/Low: } 0 \\
\text { Intermediate: }>0 \& \leq 5.6 \mathrm{~h} / \text { week } \\
\text { High: }>5.7 \mathrm{~h} / \text { week }\end{array}$ \\
\hline
\end{tabular}

Table 2. Distribution of 2,415 cases of stomach cancer and 9,722 controls according to selected covariates. Stomach cancer pooling (StoP) Project consortium. 


\begin{tabular}{|c|c|c|c|c|c|}
\hline & \multicolumn{2}{|l|}{ Cases } & \multicolumn{2}{|c|}{ Controls } & \multirow{2}{*}{$\begin{array}{l}\text { chi }^{2} \text { test } \\
\text { p value }\end{array}$} \\
\hline & $\mathrm{N}$ & $\%$ & $\mathbf{N}$ & $\%$ & \\
\hline Total & 2,415 & & 9,722 & & \\
\hline \multicolumn{6}{|l|}{ Study Center } \\
\hline Italy & 219 & 9.1 & 519 & 5.3 & \\
\hline Canada & 1,182 & 48.9 & 5,039 & 51.8 & \\
\hline Russia & 442 & 18.3 & 602 & 6.2 & \\
\hline USA & 131 & 5.4 & 131 & 1.3 & \\
\hline Spain & 441 & 18.3 & 3,431 & 35.3 & \\
\hline \multicolumn{6}{|c|}{ Physical activity ${ }^{a}$} \\
\hline None/Low & 1,155 & 47.8 & 4,180 & 43.0 & $\mathrm{p}<0.001$ \\
\hline Medium & 594 & 24.6 & 2,433 & 25.0 & \\
\hline High & 666 & 27.6 & 3,109 & 32.0 & \\
\hline \multicolumn{6}{|l|}{ Sex } \\
\hline Male & 1,570 & 65.0 & 5,058 & 52.0 & $\mathrm{p}<0.001$ \\
\hline Female & 845 & 35.0 & 4,664 & 48.0 & \\
\hline \multicolumn{6}{|l|}{ Age } \\
\hline$<=55$ & 558 & 23.1 & 3,246 & 33.4 & $\mathrm{p}<0.001$ \\
\hline (55-65] & 697 & 28.9 & 2,574 & 26.5 & \\
\hline$>65$ & 1,160 & 48.0 & 3,902 & 40.1 & \\
\hline \multicolumn{6}{|l|}{ Social class } \\
\hline Low & 1,006 & 41.7 & 3,721 & 38.3 & $\mathrm{p}<0.001$ \\
\hline Medium & 938 & 38.8 & 3,380 & 34.8 & \\
\hline High & 432 & 17.9 & 2,530 & 26.0 & \\
\hline Missing & 39 & 1.6 & 91 & 0.9 & \\
\hline \multicolumn{6}{|l|}{$\mathrm{BMI}^{\mathrm{b}}$} \\
\hline underweight & 68 & 2.8 & 174 & 1.8 & $\mathrm{p}=0.012$ \\
\hline normal weight & 973 & 40.3 & 3,875 & 39.9 & \\
\hline overweight & 867 & 35.9 & 3,593 & 37.0 & \\
\hline obese & 391 & 16.2 & 1,538 & 15.8 & \\
\hline Missing & 116 & 4.8 & 542 & 5.6 & \\
\hline \multicolumn{6}{|c|}{ Tobacco smoking } \\
\hline Never & 857 & 35.5 & 4,032 & 41.5 & $\mathrm{p}=0.001$ \\
\hline Former & 904 & 37.4 & 3,471 & 35.7 & \\
\hline Current & 454 & 18.8 & 1,951 & 20.1 & \\
\hline Missing & 200 & 8.3 & 268 & 2.8 & \\
\hline \multicolumn{6}{|c|}{ Alcohol consumption } \\
\hline Never & 494 & 20.5 & 2,102 & 21.6 & $\mathrm{p}<0.001$ \\
\hline Low & 695 & 28.8 & 3,781 & 38.9 & \\
\hline Intermediate & 552 & 22.9 & 1,881 & 19.3 & \\
\hline High & 368 & 15.2 & 663 & 6.8 & \\
\hline Missing & 306 & 12.7 & 1,295 & 13.3 & \\
\hline \multicolumn{6}{|c|}{ Vegetables and fruit intake } \\
\hline Low & 630 & 26.1 & 2,871 & 29.5 & $\mathrm{p}<0.001$ \\
\hline Medium & 786 & 32.5 & 3,041 & 31.3 & \\
\hline High & 884 & 36.6 & 3,145 & 32.3 & \\
\hline Missing & 115 & 4.8 & 665 & 6.8 & \\
\hline \multicolumn{6}{|c|}{ Occupational PA ${ }^{\mathrm{c}}$} \\
\hline Low & 348 & 14.4 & 1,588 & 16.3 & $\mathrm{p}<0.001$ \\
\hline Medium & 460 & 19.0 & 2,000 & 20.6 & \\
\hline High & 234 & 9.7 & 650 & 6.7 & \\
\hline Missing & 1,373 & 56.9 & 5,484 & 56.4 & \\
\hline \multicolumn{6}{|c|}{ History of stomach cancer } \\
\hline No & 1,028 & 42.6 & 4,326 & 44.5 & $\mathrm{p}<0.001$ \\
\hline Yes & 184 & 7.6 & 319 & 3.3 & \\
\hline Missing & 1,203 & 49.8 & 5,077 & 52.2 & \\
\hline H. Pylori status & & & & & \\
\hline Negative & 202 & 8.4 & 484 & 5.0 & $\mathrm{p}<0.001$ \\
\hline Positive & 427 & 17.7 & 2,127 & 21.9 & \\
\hline Missing & 1,786 & 74.0 & 7,111 & 73.1 & \\
\hline Histotype & & & & & \\
\hline Intestinal & 435 & 18.0 & nc & $\mathrm{nc}$ & $\mathrm{nc}$ \\
\hline Diffuse & 328 & 13.6 & $\mathrm{nc}$ & $\mathrm{nc}$ & \\
\hline Mixed & 1,394 & 57.7 & $\mathrm{nc}$ & $\mathrm{nc}$ & \\
\hline Missing & 258 & 10.7 & $\mathrm{nc}$ & $\mathrm{nc}$ & \\
\hline
\end{tabular}

Page 10/12 


\begin{tabular}{lllll} 
Subsite & 593 & 24.6 & $\mathrm{nc}$ & $\mathrm{nc}$ \\
\hline Cardia & 1,115 & 46.2 & $\mathrm{nc}$ & $\mathrm{nc}$ \\
\hline Non-Cradia & 707 & 29.3 & $\mathrm{nc}$ & $\mathrm{nc}$ \\
\hline Missing & & & &
\end{tabular}

nc: non computable

a details regarding the classification of PA variable available in table 2;

${ }^{\mathrm{b}}$ underweight (below 18.5); Normal or Healthy Weight (18.5-24.9); Overweight (25.0-29.9); Obese (30.0 and above);

${ }^{\mathrm{c}}$ available for three centers (Italy, Russia and Spain)

$\mathrm{d}$ available for two centers (Russia and Spain).

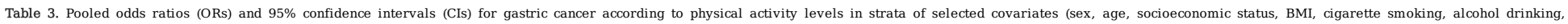
vegetables and fruit intake, occupational PA, cancer site, and cancer histotype). Stomach cancer Pooling (StoP) Project consortium.

\begin{tabular}{|c|c|c|c|c|c|c|c|c|c|c|}
\hline & \multicolumn{10}{|c|}{ Physical activity levels } \\
\hline & \multicolumn{2}{|l|}{ Low } & \multicolumn{4}{|c|}{ Intermediate } & \multicolumn{4}{|l|}{ High } \\
\hline & $\mathrm{Ca}: \mathrm{Co}$ & $\mathrm{OR}^{\mathrm{a}}$ & $\mathrm{Ca}: \mathrm{Co}$ & OR $(95 \% \mathrm{CI})$ & $I^{2}(\%)$ & $\mathrm{p}^{\mathrm{b}}$ & $\mathrm{Ca}: \mathrm{Co}$ & OR $(95 \% \mathrm{CI})$ & $I^{2}(\%)$ & $\mathrm{p}^{\mathrm{b}}$ \\
\hline Overall & $1155 / 4180$ & 1.00 & $594 / 2433$ & $0.90(0.72,1.13)$ & 49.7 & & $666 / 3109$ & $0.72(0.57,0.91)$ & 42.9 & \\
\hline \multicolumn{11}{|l|}{ Gender } \\
\hline Male & $762 / 2080$ & 1.00 & $361 / 1180$ & $0.88(0.63,1.23)$ & 58.6 & 0.492 & $447 / 1798$ & $0.65(0.53,0.79)$ & 10.5 & 0.304 \\
\hline Female & $393 / 2100$ & 1.00 & $233 / 1253$ & $1.01(0.82,1.24)$ & 0 & & $219 / 1311$ & $0.82(0.55,1.22)$ & 46.3 & \\
\hline \multicolumn{11}{|l|}{ Age (years) } \\
\hline$\leq 55$ & $257 / 1451$ & 1.00 & $159 / 875$ & $1.06(0.82,1.36)$ & 0 & 0.52 & $142 / 920$ & $0.75(0.57,0.99)$ & 0 & 0.961 \\
\hline$>55 \& \leq 65$ & $315 / 1046$ & 1.00 & $180 / 682$ & $0.90(0.65,1.24)$ & 20.7 & & $202 / 846$ & $0.80(0.50,1.30)$ & 50.6 & \\
\hline$>65$ & $583 / 1683$ & 1.00 & $255 / 876$ & $0.81(0.51,1.27)$ & 67.1 & & $322 / 1343$ & $0.72(0.39,1.32)$ & 79.6 & \\
\hline \multicolumn{11}{|l|}{ Social class } \\
\hline Low & $531 / 1641$ & 1.00 & $231 / 938$ & $0.81(0.58,1.15)$ & 35.7 & 0.824 & $244 / 1142$ & $0.66(0.53,0.81)$ & 0 & 0.47 \\
\hline Intermediate & $390 / 1351$ & 1.00 & $260 / 896$ & $0.91(0.73,1.13)$ & 0 & & $288 / 1133$ & $0.78(0.63,0.97)$ & 0 & \\
\hline High & $207 / 1137$ & 1.00 & $95 / 575$ & $0.83(0.58,1.20)$ & 8.5 & & $130 / 818$ & $0.65(0.49,0.87)$ & 0 & \\
\hline \multicolumn{11}{|l|}{ BMI } \\
\hline Normal weight & $452 / 1603$ & 1.00 & $246 / 960$ & $0.87(0.71,1.08)$ & 0 & 0.934 & $275 / 1312$ & $0.66(0.48,0.92)$ & 26.5 & 0.933 \\
\hline Overweight & $428 / 1527$ & 1.00 & $196 / 893$ & $0.83(0.52,1.34)$ & 64.8 & & $243 / 1173$ & $0.70(0.56,0.86)$ & 0 & \\
\hline Obese & $203 / 707$ & 1.00 & $91 / 402$ & $0.80(0.53,1.21)$ & 10.5 & & $97 / 429$ & $0.72(0.51,1.01)$ & 0 & \\
\hline \multicolumn{11}{|c|}{ Cigarette smoking status } \\
\hline Never & $372 / 1748$ & 1.00 & $235 / 1048$ & $0.96(0.76,1.20)$ & 0 & 0.896 & $250 / 1236$ & $0.86(0.63,1.19)$ & 29.5 & 0.267 \\
\hline Former & $436 / 1391$ & 1.00 & $197 / 828$ & $0.87(0.61,1.26)$ & 33.9 & & $271 / 1252$ & $0.63(0.52,0.77)$ & 0 & \\
\hline Current & $232 / 920$ & 1.00 & $120 / 497$ & $0.91(0.68,1.24)$ & 0 & & $102 / 534$ & $0.65(0.46,0.90)$ & 0 & \\
\hline \multicolumn{11}{|c|}{ Alcohol drinking status } \\
\hline Never & $213 / 893$ & 1.00 & $139 / 584$ & $0.91(0.69,1.20)$ & 0 & 0.838 & $142 / 625$ & $0.69(0.35,1.34)$ & 56.5 & 0.939 \\
\hline \multirow[t]{4}{*}{ Ever } & $791 / 2669$ & 1.00 & $376 / 1523$ & $0.87(0.63,1.21)$ & 63.9 & & $448 / 2133$ & $0.71(0.53,0.96)$ & 51.7 & \\
\hline & \multicolumn{10}{|c|}{ Physical activity levels } \\
\hline & \multicolumn{2}{|l|}{ Low } & \multicolumn{2}{|c|}{ Intermediate } & & & \multicolumn{4}{|l|}{ High } \\
\hline & $\mathrm{Ca}: \mathrm{Co}$ & $\mathrm{OR}^{\mathrm{a}}$ & $\mathrm{Ca}: \mathrm{Co}$ & OR $(95 \%$ CI) & $I^{2}(\%)$ & $\mathrm{p}$ & $\mathrm{Ca}: \mathrm{Co}$ & OR $(95 \%$ CI) & $\mathrm{I}^{2}(\%)$ & $\mathrm{p}$ \\
\hline \multicolumn{11}{|c|}{ Vegetables and fruit intake } \\
\hline Low & $347 / 1339$ & 1.00 & $150 / 783$ & $0.84(0.65,1.07)$ & 0 & 0.866 & $133 / 749$ & $0.65(0.40,1.05)$ & 36.4 & 0.859 \\
\hline Intermediate & $358 / 1234$ & 1.00 & $197 / 782$ & $0.90(0.52,1.55)$ & 70.4 & & $231 / 1025$ & $0.72(0.46,1.13)$ & 49.2 & \\
\hline High & $382 / 1235$ & 1.00 & $219 / 733$ & $0.92(0.73,1.16)$ & 0 & & $283 / 1177$ & $0.76(0.57,1.01)$ & 19.6 & \\
\hline \multicolumn{11}{|l|}{ Occupational $\mathrm{PA}^{\mathrm{c}}$} \\
\hline Low & $170 / 770$ & 1.00 & $114 / 433$ & $1.21(0.75,1.97)$ & 48.5 & 0.46 & $64 / 385$ & $0.87(0.35,2.16)$ & 72.4 & 0.863 \\
\hline Intermediate & $228 / 844$ & 1.00 & $113 / 498$ & $0.86(0.61,1.21)$ & 0 & & $119 / 658$ & $0.73(0.44,1.22)$ & 36.3 & \\
\hline High & $105 / 290$ & 1.00 & $61 / 158$ & $0.82(0.48,1.37)$ & 0 & & $68 / 202$ & $0.65(0.37,1.14)$ & 0 & \\
\hline \multicolumn{11}{|l|}{ Anatomical type } \\
\hline Cardia & $251 / 4180$ & 1.00 & $133 / 2433$ & $0.87(0.65,1.17)$ & 10.7 & 0.531 & 209/3109 & $0.84(0.68,1.05)$ & 0 & 0.097 \\
\hline Non Cardia & $579 / 4180$ & 1.00 & $263 / 2433$ & $0.77(0.60,0.98)$ & 31.6 & & $273 / 3109$ & $0.59(0.42,0.84)$ & 56.4 & \\
\hline \multicolumn{11}{|l|}{ Histological type } \\
\hline Intestinal & $171 / 4180$ & 1.00 & $99 / 2433$ & $0.99(0.62,1.56)$ & 41.2 & 0.339 & $165 / 3109$ & $1.27(0.77,2.09)$ & 56.7 & 0.115 \\
\hline Diffuse & $147 / 4180$ & 1.00 & $95 / 2433$ & $1.15(0.83,1.59)$ & 0 & & $86 / 3109$ & $0.82(0.48,1.41)$ & 40.6 & \\
\hline Mixed & $691 / 4180$ & 1.00 & $344 / 2433$ & $0.86(0.69,1.07)$ & 13.3 & & $359 / 3109$ & $0.68(0.50,0.93)$ & 21 & \\
\hline H. Pylori status & & & & & & & & & & \\
\hline Negative & $69 / 189$ & 1.00 & $56 / 150$ & $0.87(0.54,1.43)$ & 0 & 0.862 & $77 / 145$ & $1.14(0.70,1.88)$ & 0 & 0.258 \\
\hline Positive & $195 / 872$ & 1.00 & $118 / 530$ & $0.94(0.46,1.93)$ & 79.7 & & $114 / 725$ & $0.71(0.37,1.36)$ & 75.2 & \\
\hline Gastric Cancer I & ory ${ }^{e}$ & & & & & & & & & \\
\hline No & $473 / 1927$ & 1.00 & $269 / 1080$ & $1.04(0.79,1.38)$ & 30.5 & 0.578 & $286 / 1319$ & $0.74(0.58,0.95)$ & 0 & 0.922 \\
\hline Yes & $78 / 123$ & 1.00 & $51 / 92$ & $0.67(0.15,3.07)$ & 78.5 & & $55 / 104$ & $0.68(0.13,3.65)$ & 71 & \\
\hline
\end{tabular}

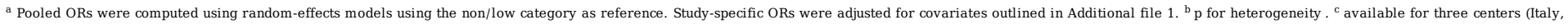
Spain and Russia). ${ }^{\mathrm{d}}$ available for two centers (Russia and Spain). ${ }^{\mathrm{e}}$ Information for cancer history was not available for Canadian center. 
Figures

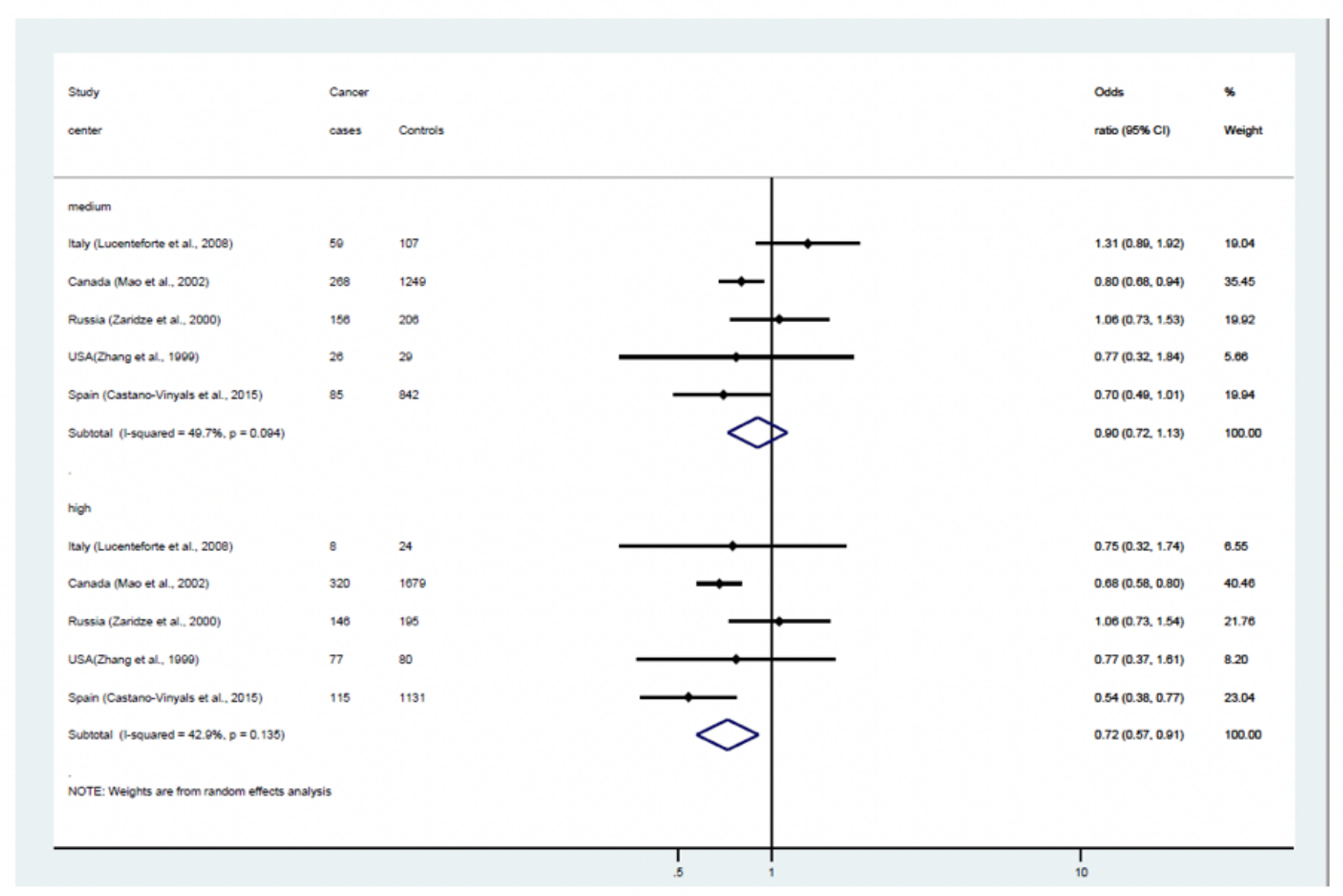

\section{Figure 1}

Study-specific and adjusted pooled odds ratios (ORs) and corresponding 95\% confidence intervals of GC risk for intermediate and high PA levels. The combined estimate is based on a random-effects model

\section{Supplementary Files}

This is a list of supplementary files associated with this preprint. Click to download.

- Additionalfile1.docx 